\title{
Excellent Survival after Reirradiation
}

National Cancer Institute

\section{Source}

National Cancer Institute. Excellent Survival after Reirradiation. NCI Thesaurus. Code C127863.

A score of 0 on the Combs Prognostic Index scale. 